\title{
Crowd-Out in the State Children's Health Insurance Program (SCHIP): Incidence, Enrollee Characteristics and Experiences, and Potential Impact on New York's SCHIP
}

\author{
Laura P. Shone, Paula M. Lantz, Andrew W. Dick, \\ Michael E. Chernew, and Peter G. Szilagyi
}

Background. The extent to which the State Children's Health Insurance Program (SCHIP) crowds our private insurance is poorly understood.

Objective. To assess the incidence of crowd-out and enrollee characteristics associated with crowd-out.

Data. Parent telephone survey for 2,644 children after enrollment in NY SCHIP.

Measures and Analyses. Crowd-out is measured based on enrollee reports of coverage (and loss of coverage) before SCHIP. Multivariate logistic regression is used to relate crowd-out to enrollee characteristics.

Principal Findings. Only 7.1 percent of SCHIP enrollees dropped private coverage $\leq 6$ months before SCHIP, suggesting relatively modest crowd-out. Crowd-out was associated with some enrollee traits including income, but not with health status.

Implications. Most movement from private to public insurance in NY was not crowdout. Under current program structure in NY, crowd-out concerns should not dampen enthusiasm for SCHIP.

Key Words. waiting periods, crowd-out, substitution, uninsured children, children's health insurance, state children's health insurance program, SCHIP

The State Children's Health Insurance Program (SCHIP) offers public coverage to eligible children who would otherwise remain uninsured, (Blumberg 2003). Public coverage expansions can displace or "crowd-out" private health insurance if some individuals drop private coverage to enroll in public programs (Davidson, Blewett, and Call 2004).

The incidence of crowd-out is important if public funds support coverage for children who could obtain (private) insurance elsewhere (Alteras 
2001). Strategies to deter crowd-out were required in SCHIP. Many states chose waiting periods, which specify a mandatory uninsured gap to qualify for SCHIP (Agency for Healthcare Research and Quality 1998a, b). The regulations for use of waiting periods depend on states' SCHIP models: separate SCHIP, Medicaid expansion, or combination (Rosenbach et al. 2003). At the time of this study in 2000, 37 states had waiting periods averaging 3-6 months and nine were using existing Medicaid provisions, which do not allow waiting periods without approved federal waiver (Centers for Medicare and Medicaid Services 2003). New York was one of only four separate SCHIP or combination program states without waiting periods (National Conference of State Legislatures 2003). In 2006, 35 states had waiting periods, commonly between 3-6 months (Congressional Budget Office 2007).

New York measured and had evidence of minimal crowd-out during the mid-1990s in their SCHIP-precursor program, Child Health Plus. Therefore, it was approved in 1997 as the state's SCHIP plan with continued monitoring, but without a waiting period (Rosenbach et al. 2003). New York's definition of crowd-out as approved in the state plan stipulates that: (1) the last insurance before SCHIP was private; (2) it covered the child within $\leq 6$ months before SCHIP; and (3) was lost because "cost of [prior insurance] went up or SCHIP is [cheaper] or [better] than [prior insurance]" (Centers for Medicare and Medicaid Services 2003; Rosenbach et al. 2003). Other reasons for coverage change including changes in employment, family (marital) structure, relocation, loss/death of a spouse or parent, or other loss of access to employer benefits, are among the allowable exemptions to waiting periods in other states (Rosenbach et al. 2003), and therefore are not considered crowdout in New York.

Two terms- "substitution" and "crowd-out"-have been used interchangeably despite important distinctions that have policy implications. "Substitution" describes shifts in aggregate toward public and away from

Address correspondence to Laura P. Shone, Dr.P.H., M.S.W., Assistant Professor of Pediatrics and Clinical Nursing, Department of Pediatrics, School of Nursing, and the Robert J. Haggerty Health Services Research Laboratories, University of Rochester School of Medicine and Dentistry, 601 Elmwood Avenue, Box 777, Rochester, NY. Paula M. Lantz, Ph.D., M.S., Professor and Chair, is with the Department of Health Management and Policy, Faculty Associate, Institute for Social Research, University of Michigan, Ann Arbor, MI. Andrew W. Dick, Ph.D., Senior Economist, is with the RAND Corporation, Pittsburgh, PA. Michael E. Chernew, Ph.D., Professor, Harvard Medical School, is with the Department of Health Care Policy, Boston, MA. Peter G. Szilagyi, M.D., M.P.H., Chief, Division of General, Pediatrics, Professor of Pediatrics, is with the Department of Pediatrics and Strong Children's Research Center, Department of Community and Preventive Medicine, University of Rochester School of Medicine and Dentistry, Rochester, NY. 
private coverage after a public health insurance expansion (Dubay 1999). Some substitution can be explained by life changes such as parent employment or marital status that sever links to private insurance; in contrast, "crowdout" is one type of substitution that occurs only when children who could have private insurance enroll in public coverage instead (Davidson, Blewett, and Call 2004). Crowd-out typically refers to a percentage of total enrollees (Sommers et al. 2006), however, data sources that are commonly used to examine substitution lack the detail needed to make the important distinction between substitution and crowd-out (Dubay 1999; Davidson, Blewett, and Call 2004).

Most substitution estimates use large datasets and rely on complex statistical methods to identify income-eligible children, compare coverage trends, and attempt to determine what share of children might have had private coverage if public options had not expanded (Sommers et al. 2006). These studies have used various data sources, definitions, and methods and have produced various estimates (Dubay 1999; Shone and Szilagyi 2005). Cross-sectional estimates range from $<20$ to $\geq 50$ percent compared with $<10$ percent from analyses of longitudinal or survey data (Feinberg et al. 2001). These studies provide few explanations for insurance transitions; although limited more by data than method, explanations are essential to understanding the extent and implications of crowd-out in SCHIP (Davidson, Blewett, and Call 2004).

Before the passage of SCHIP in 1997, several states had existing SCHIPlike health insurance programs to provide free or low-cost public coverage to low-income uninsured children whose parents earned too much to qualify for Medicaid. Participant surveys have measured enrollees' health insurance access and coverage before joining some of these programs. These studies reported that: 5 percent of Florida enrollees had private coverage within $\leq 12$ months (Shenkman et al. 1999); 7 percent of enrollees in Minnesota dropped private coverage to enroll in a state program (Call et al. 1997); and 4 percent of enrollees in Massachusetts held private coverage before joining a state plan (Feinberg et al. 2001). Following the passage of SCHIP, results from studies of SCHIP programs themselves found that 22 percent of Kansas enrollees had private coverage within $\leq 12$ months (Allison et al. 2003), and 8 percent of California enrollees dropped employer-based coverage within 3 months before SCHIP (Hughes, Angeles, and Stilling 2002). In Florida, an estimated 18 percent of enrollees were eligible for an employer-based plan when surveyed after enrollment (Nogle and Shenkman 2004). One multistate study found that 72 percent of enrollees lacked access to private coverage for $\geq 6$ 
months before SCHIP. Of 28 percent who had private coverage during that time, only half lost it for reasons that the authors classified as crowd-out (Sommers et al. 2006). These studies help explain insurance transitions, yet lack detail about enrollee characteristics or experiences.

This study is possible in NY because crowd-out monitoring has occurred since the inception of SCHIP, yet no waiting period deterrent has ever been in place in NY. New York SCHIP policy states that a 6 -month waiting period will be considered if the statewide crowd-out incidence averages 8 percent or greater in any consecutive 9-month period (Rosenbach et al. 2003). We report findings from a statewide study of NY's SCHIP that was part of the Children's Health Insurance Research Initiative $\left(\mathrm{CHIRI}^{\mathrm{TM}}\right)$. As part of the statewide enrollee interview, we included the crowd-out questions used on NY's application forms for ongoing crowd-out monitoring. Assuming that children who meet criteria for crowd-out could have been subject to a waiting period if one had been in place, our goals were to analyze the incidence of crowd-out using the state's methods in a context that was removed from the application process, and to identify possible disparities in the characteristics of children who could potentially be affected by waiting periods.

\section{OBJECTIVES}

With a unique dataset, our objectives were: (1) to assess prior insurance coverage and reasons for loss among enrollees in NY SCHIP; and (2) to estimate the incidence of crowd-out; and (3) to identify associations between crowd-out and enrollee characteristics to identify potential disparities.

\section{METHODS}

\section{Sample, Subjects, and Data Collection}

Our sampling and data collection methods are described in detail elsewhere (Dick et al. 2002). Using state administrative files to identify new enrollees in SCHIP between November 1, 2000 and March 31, 2001, we generated a random sample of 9,101 unique children (one index child per household), stratified by age group (0-5, 6-11, and 12-18 years) and region of NY (New York City [NYC], NYC Environs, Upstate Urban, and Upstate Rural) based on U.S. Bureau of the Census standard metropolitan statistical areas. The 
National Opinion Research Center conducted telephone interviews in English and Spanish between March 15, 2001 and September 15, 2001.

Measures to Assess Crowd-Out used NY State's policy criteria for coverage history before SCHIP (Medicaid, private, none), time since coverage loss, and reasons for loss of prior insurance including: employment or marital status change, employer change in benefit offerings, or parent report that SCHIP was cheaper or offered better benefits than the child's last insurance We used the state's definition that crowd-out occurred when private coverage held within 6 months or less before SCHIP was lost because "the cost of [other] insurance went up and I could not afford it any more," or "SCHIP is cheaper," or "SCHIP has better benefits [than last insurance]" (Rosenbach et al. 2003; Centers for Medicare and Medicaid Services 2003).

Measures of Enrollee Characteristics included child age and race/ethnicity; household income, highest education and employment status of either parent, and other household factors. Child health status measures included diagnosis of asthma (National Heart, Lung, Blood Institute 1997) or chronic health conditions (Child and Adolescent Health Measurement Initiative 2003), overall health status rating, and measures of parental worry about the child's health.

\section{Analyses}

We calculated proportions and standard errors to describe health insurance experiences before SCHIP and incidence of crowd-out. We compared proportions and standard errors using $\chi^{2}$ statistics to examine variation in incidence by key demographic characteristics including child age, race/ ethnicity, and health status. We performed multivariate logistic regression to identify significant independent associations between enrollee characteristics and crowd-out status (yes/no). All analyses were performed using the SVY commands in Stata 10.0 to account for the complex sampling design and generate appropriately weighted statewide estimates (StataCorp 2007).

\section{RESULTS}

Of 9,101 index children in the sample frame, we successfully contacted 7,293 (80 percent), and 3,658 (50 percent) of those were eligible for the study. Disposition of 3,658 eligible participants included 957 refusals (26 percent) and 487 other nonresponses due to language barrier or 
unavailability (e.g., travel, incarceration) for interview (13 percent). Of 3,658 eligibles, 2,701 gave consent (74 percent), with 2,644 full interviews completed (72 percent).

\section{Time Uninsured, Prior Health Insurance, and Coverage Loss}

As shown in Table 1, 62 percent of enrollees were uninsured for a year or more, and a third had never been covered by health insurance before SCHIP. Approximately 48 percent reported private and approximately 44 percent reported Medicaid as the last insurance held before SCHIP.

Table 2 shows reasons for coverage loss among new SCHIP enrollees. The first results column shows the frequency for each reason among those $(n=738)$ who had private insurance within 6 months before SCHIP. Among this group, 25 percent lost coverage for reasons that met the definition of crowd-out (i.e., the cost of insurance went up, SCHIP costs less, or SCHIP has better benefits). However, estimates of crowd-out in SCHIP programs and comparisons of crowd-out across states are typically calculated using all enrollees (as opposed to only those who had private insurance before SCHIP) as the denominator (Allison et al. 2003; Call et al. 1997; Feinberg et al. 2001; Hughes, Angeles, and Stilling 2002; Shenkman et al. 1999). Using this method, the estimate of crowd-out in NY is 7.1 percent (column 2, Table 2). Estimating crowd-out as a percent of total enrollees is consistent with New York's threshold policy indicating that "the State will impose a waiting period of

Table 1: Time Uninsured and Source of Prior Health Coverage among New SCHIP Enrollees

\begin{tabular}{lr}
\hline & $\begin{array}{c}\text { Proportion (SE) } \\
(n=2,644)\end{array}$ \\
\hline Uninsured > 12 months before SCHIP* & $61.7(2.4)$ \\
Uninsured 6-12 months & $4.9(1.1)$ \\
Uninsured <6 months & $33.3(3.8)$ \\
Last insurance held before SCHIP & \\
Private & $47.5(3.1)$ \\
Medicaid & $43.9(3.2)$ \\
Other (e.g., Military; CHAMPUS; TRICARE, etc.) & $9.3(2.6)$ \\
\hline
\end{tabular}

*Includes $33.5 \%$ that were never insured in child's lifetime, plus $28.2 \%$ who had prior coverage with an uninsured gap of $\geq 12$ months.

${ }^{\dagger}$ Families could move from prior Medicaid to SCHIP if they experience an increase in income (due to employment or marital change and others).

SCHIP, State Children's Health Insurance Program. 
Table 2: Reasons for Coverage Loss among New SCHIP Enrollees*

\begin{tabular}{|c|c|c|}
\hline & $\begin{array}{c}\text { Private Insurance } \\
<6 \text { Months before } \\
\text { SCHIP }(n=738) \\
27.9(2.0)\end{array}$ & $\begin{array}{c}\text { All Enrollees } \\
(n=2,644) \\
100(0.0)\end{array}$ \\
\hline \multicolumn{3}{|l|}{ Reasons for Coverage Loss } \\
\hline 1. Parent lost or changed jobs & $55.2(4.1)$ & $27.8(2.6)$ \\
\hline $\begin{array}{l}\text { 2. Changed or lost spouse (marital status change or } \\
\text { death) }\end{array}$ & $8.9(1.2)$ & $7.4(1.3)$ \\
\hline $\begin{array}{l}\text { 3. Employer stopped offering or terminated all health } \\
\text { coverage }\end{array}$ & $16.7(4.5)$ & $7.4(2.1)$ \\
\hline $\begin{array}{l}\text { 4. Employer stopped offering or terminated child } \\
\text { health coverage }\end{array}$ & $6.1(1.2)$ & $3.1(1.0)$ \\
\hline 5. Hassle/too much paperwork & $5.1(1.3)$ & $14.4(2.1)$ \\
\hline $\begin{array}{l}\text { 6. Other (e.g., relocation, parent disability, dropped by } \\
\text { other plan) }\end{array}$ & $11.6(2.0)$ & $20.4(2.2)$ \\
\hline \multicolumn{3}{|l|}{ Crowd-Out $^{\dagger}$ ( $>1$ of $7-9$, below, without any other reasons $1-6$ ) } \\
\hline $\left.\begin{array}{l}\text { 7. Cost of other insurance went up } \\
\text { 8. SCHIP costs less } \\
\text { 9. SCHIP has better benefits }\end{array}\right\}$ & $25.3(3.6)$ & $7.1(1.1)$ \\
\hline
\end{tabular}

*Crowd-out in NY includes the "[percent] of total enrollment [that has] dropped employer based health insurance to enroll in [SCHIP]" (Centers for Medicare and Medicaid Services, New York Title XXI Program Fact Sheet, 2007).

†Percentages do not sum to 100 because respondents could give more than one reason.

SCHIP, State Children's Health Insurance Program.

uninsurance if the State finds that greater than 8 percent of total enrollment has dropped employer based health insurance to enroll in [SCHIP]" (Centers for Medicare and Medicaid Services, New York Title XXI Program Fact Sheet 2007).

Parental job change or loss was the dominant reason for coverage loss, affecting nearly a third of all enrollees (Table 2). In addition, 10 percent of all enrollees lost prior coverage because an employer terminated health coverage options-either altogether (7 percent) or just for children (3 percent) (Table 2). Such reasons have been classified as involuntary coverage loss (Sommers et al. 2006). In contrast, parents of 7.1 percent of enrollees reported one or more reasons that meet the definition of crowd-out as the reason for loss of private coverage within the 6 months before SCHIP enrollment. These reasons include: (1) "the cost of [other] insurance went up and I could not afford it any more," (2) "SCHIP is cheaper," or (3) "SCHIP has better benefits [than last insurance]." Any report of one or more of these reasons without report of any other reason was classified as crowd-out. 


\section{Crowd-Out and Enrollee Characteristics (Table 3)}

Crowd-out was greatest among children who were white or above the lowest income tier; whose parents went beyond high school or graduated from college; whose parents were working full-time; and whose mothers were born in the United States (Table 3). Crowd-out was lower among parents who worried more about their child's health or felt that their child was less healthy than other children. Crowd-out did not vary significantly by child age group, residence with a single parent, parent perception of overall health status, or presence of a chronic health problem or asthma.

We performed multivariate analyses to identify potential disparities in the characteristics of children who have increased odds of crowd-out and thus might be subject to waiting periods (Table 3). Our multivariate results confirm our bivariate results for all except parental worry about the child. Adjusting for covariates, children had significantly greater odds of crowd-out if they were: age $3-5$ years; perceived by parents as not being any "less healthy than other children"; living with parents who had education beyond high school or were working full-time, or children of US-born mothers. Hispanic children had significantly lower odds of crowd-out. Importantly, even after adjusting for covariates, there were no significant differences in crowd-out by overall health status, report of prior serious illness, or presence of special health needs (CSHCN) or asthma.

\section{DISCUSSION}

This study examined crowd-out in SCHIP in ways that have not been possible historically. Our results provide new insights regarding how crowd-out might affect SCHIP programs, the potential effects of waiting periods on children who could be subject to them, and how to measure crowd-out.

Twenty-eight percent of enrollees lost private insurance in the 6 months before entering SCHIP. After accounting for coverage change that is not crowd-out (job change, family/marital status change, relocation, etc), only 7.1 percent of enrollees had reasons for enrolling in SCHIP that were classified by NY as crowd-out. This classification scheme and both resulting percentages are nearly identical to that reported in a 10-state study (Sommers et al. 2006). This level of individual detail about reasons for coverage change is unusual, yet is essential to distinguish children that could have private insurance elsewhere from children who lack options and could otherwise be uninsured - the target population of SCHIP (Balanced Budget Act 1997). 


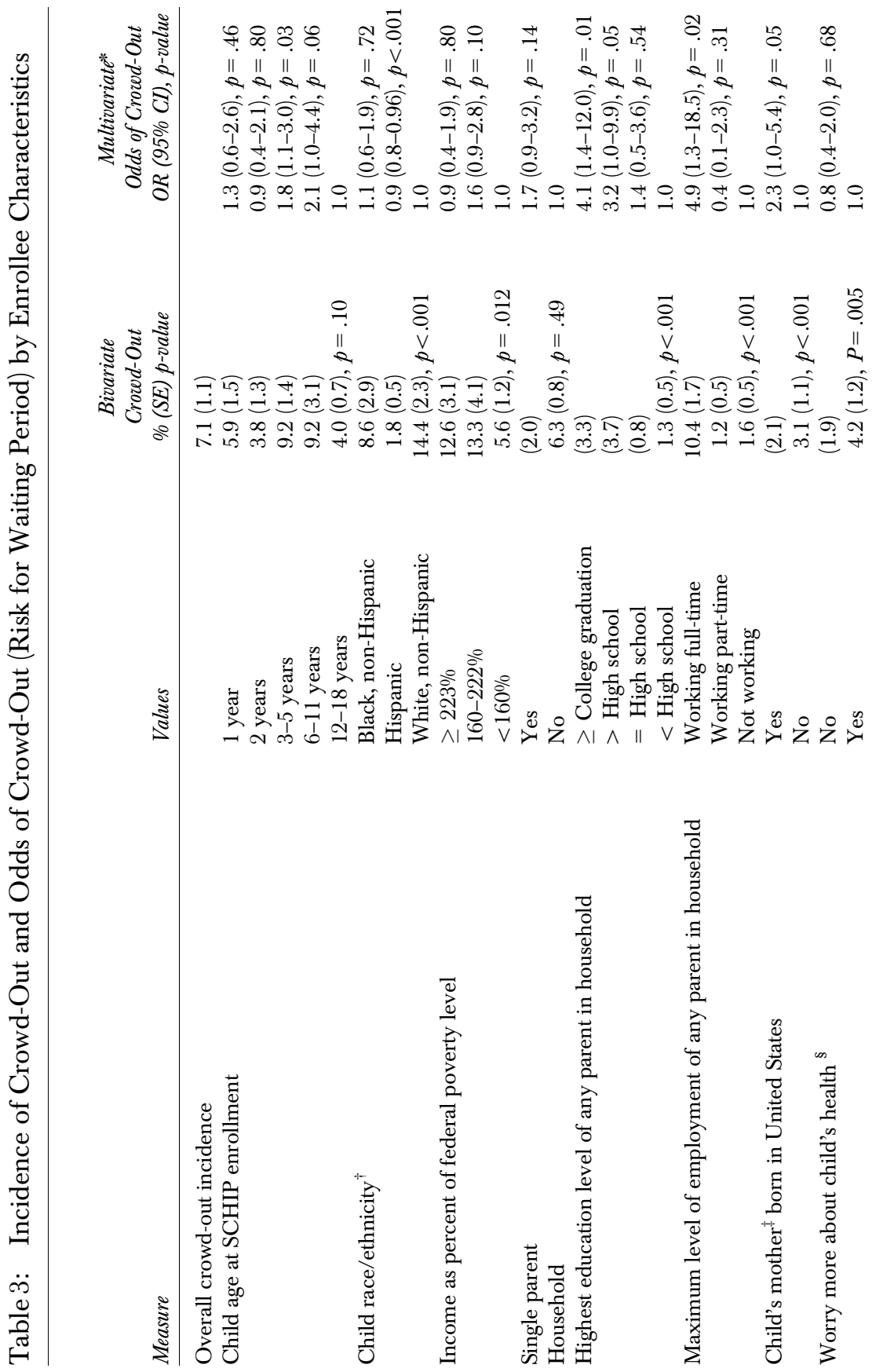




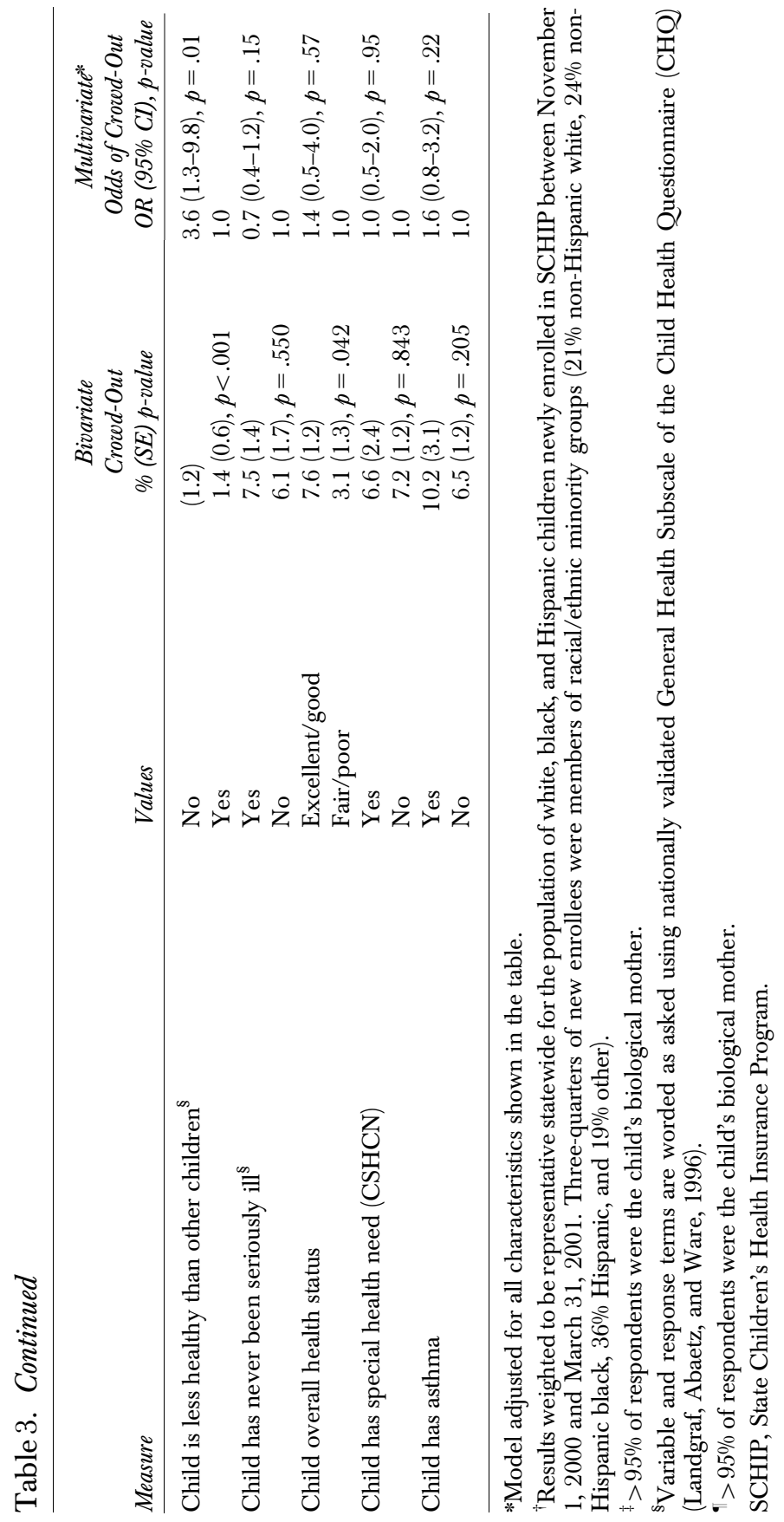


It would be concerning if the group that could be affected by waiting periods disproportionately comprised children with poorer health status or those from racial/ethnic minority groups. Instead, we found that the mix of children who could be affected by waiting periods if they were to be implemented resembles the overall mix of SCHIP enrollees (Brach et al. 2003). More crowd-out occurred among white children at higher levels of income, parent education, or employment. Though not statistically significant, this population of children included clinically significant prevalence of chronic health care needs ( 7 percent) and asthma (10 percent). From a policy perspective, both require access to regular medical care (Rosenbaum and Budetti 2003). The primary concern about waiting periods is that they can harm children by enforcing or prolonging gaps in insurance coverage (Glied 2002; Ku and Ross 2002; Olson, Tang, and Newacheck 2005). Uninsured children have experienced health complications while waiting for SCHIP coverage (Silberman et al. 2003). Thus, an increased prevalence of waiting periods among those with chronic health care needs could have clinical ramifications for children who have ambulatory-sensitive conditions such as asthma (Satchell and Pati 2005).

The potential value of a waiting period to deter crowd-out depends on the methods used for defining and monitoring crowd-out. New York does not have a waiting period, but they do have detailed monitoring information that distinguishes between coverage loss that may be preventable and coverage loss that probably is not. This difference is visible in New York. Although nearly 30 percent of new enrollees moved from private to public coverage within the 6-month period before enrolling in SCHIP, most lost private coverage for reasons other than crowd-out, whereas only 7 percent chose SCHIP because it was "cheaper or better" than the child's prior private coverage. Some portion of the latter may have been preventable; however, it is unlikely that all reasons for the loss of private coverage before enrolling in SCHIP could have been prevented or deterred with a waiting period in place. The value of waiting periods may be that they provide incentives to parents to keep rather than drop private coverage. Nonetheless, waiting periods will not deter families who lose coverage for reasons beyond their control from enrolling in SCHIP. Policies for measuring and monitoring crowd-out must include detail similar to the New York study to ensure that children who have lost coverage for reasons other than true crowd-out are not subject to potentially harmful gaps in insurance coverage. 


\section{LIMITATIONS}

This study examines a sample of children who were: successfully enrolled in NY's SCHIP; new enrollees versus longer-term enrollees; white, black, or Hispanic; whose parents spoke either English or Spanish; and whom we were able to locate and interview, and cannot be generalized more broadly. Our study involved a longitudinal pre-post study of new enrollees during the year before and year during SCHIP. We did not sample longer-term enrollees, and results over longer periods may vary.

We used instruments and measures that were nationally validated for self-report of health care and insurance information, however, limitations of self-report apply.

Our study cannot determine the counterfactual. There is no way to know what parents would have done if waiting periods had been in place or if SCHIP did not exist. This is a challenge in measuring crowd-out and waiting periods alike, because most studies rely on sources that lack individual-level data (Davidson, Blewett, and Call 2004), or because it is not possible to identify and sample families who have already done something else. We cannot distinguish those who, under different circumstances, may have kept existing coverage, obtained other coverage, or remained uninsured.

Although our results provide new information about prior health insurance, enrollee characteristics and health experiences in conjunction with crowd-out, these results may differ under different SCHIP eligibility criteria. Further studies to address these questions are needed.

\section{CONCLUSIONS AND POLICY IMPLICATIONS}

After accounting for private coverage loss that is not crowd-out, only 7 percent of enrollees had reasons for enrolling in SCHIP that were classified by NY as crowd-out. Some persons who lose private insurance have private coverage alternatives, whereas others lack those options. The SCHIP target population includes the latter. This group is dynamic, and the profile of characteristics and experiences of uninsured children will evolve as unraveling of private coverage progresses up the income scale (Strom 2003).

Our analyses of enrollee characteristics may offer insight to states in considering waiting period policies in terms of better understanding the different reasons for coverage change. The variety of policy options available to balance increasing public coverage need with limited fiscal resources 
suggests that variation in states' waiting period policies may continue. It is therefore essential to monitor individual characteristics and experiences to understand specific reasons for movement from private to public coverage and to distinguish preventable movement from other market forces. New research should examine the effects of state policy decisions about SCHIP eligibility, crowd-out, exclusions, and waiting periods as policies evolve.

Although measurement of crowd-out is confounded in states where deterrents already exist, results in other states could be similar to our results in NY. A study in 10 states including NY found the same degree of overall movement from private to public coverage within the 6 months before SCHIP (just under 30 percent). After classifying reasons for coverage change, they found the same smaller proportion of 7 percent crowd-out. Results could also vary across states and over time with market changes and secular trend. Our results demonstrate that ongoing detailed monitoring is important in distinguishing crowd-out from these other factors in movement from private to public coverage.

Crowd-out in NY could represent an upper bound relative to other states, because NY has one of the higher income-eligibility thresholds and does not have a waiting period deterrent in place. Then again, because income thresholds in NY reflect, in part, the higher cost of living in NY, our results could be on par with other states after accounting for other market differences in access to and costs of creditable private coverage. Ongoing detailed measurement of individual reasons for coverage change are essential to answer this question.

Monitoring is essential for implementation of waiting periods, and detailed monitoring may improve the precision of how waiting period policies are applied. Monitoring in NY, via the application form, is institutionalized part of the application process at little to no added cost. States with waiting periods use various procedures to verify other coverage, ranging from individual contact to cross-linkage of administrative data (Rosenbach et al. 2003). These procedures would add to the costs and time needed to process applications if implemented in NY.

Our results have implications for both state and federal policy makers. Several states have proposed increases in income eligibility levels, raising questions about possible crowd-out, and crowd-out emerged as the major point of contention in federal SCHIP reauthorization. Our results add to understanding of the range of estimates, emphasize the role of monitoring and importance of measurement methods, and illustrate some distinctions that 
are possible and necessary to understand the incidence of crowd-out and the potential role and impact of waiting periods in SCHIP policy.

\section{ACKNOWLEDGMENTS}

This work was funded by the Department of Health and Human Services Grant \# HS-10450-03, Agency for Healthcare Research and Quality, David and Lucile Packard Foundation, and Health Resources and Services Administration.

Disclosures: None.

Disclaimer: The contents reflect the opinion of the authors only, and not their respective institutions or the project funders.

Results of the study were presented in part at the annual research meeting of AcademyHealth, June 26, 2005, Boston, MA.

\section{REFERENCES}

Agency for Healthcare Research and Quality. 1998a. "When Does Crowd-Out Occur?” [accessed May 2003]. Available at http://www.ahrq.gov/chip/content/ crowd_out/crowd_out_define.htm

—. 1998b. "Regulatory Guidance Regarding Crowd-Out under SCHIP" [accessed October 2002]. Available at http://www.ahrq.gov/chip/content/crowd_out/ crowd_out_regulations.htm

Allison, R. A., R. F. St Peter, C. C. Huang, and B. LaClair. 2003. Kansas Health Institute Research Brief: Do Children Enrolling in Public Health Insurance Have Other Options? Findings from the HealthWave Evaluation Project. KHI/RB 03-2. Topeka, KS: Kansas Health Institute.

Alteras, T. T. 2001, "Understanding the Dynamics of Crowd-out: Defining Public/ Private Coverage Substitution for Policy and Research" [accessed June 2003]. Available at http://www.hcfo.net/pdf/crowdout.pdf

Balanced Budget Act of 1997-State Children's Health Insurance Program. Public Law 105-33 and 105-34. 10-1-1997. Title XXI of the Social Security Act. 4-82003.

Blumberg, L. J. 2003. "Balancing Efficiency and Equity in the Design of Coverage Expansions for Children." Future of Children 13 (1): 205-211.

Brach, C., E. M. Lewit, K. Van Landeghem, J. Bronstein, A. W. Dick, K. S. Kimminau, B. Laclair, E. Shenkman, L. P. Shone, N. Swigonski, P. G. Szilagy, and the Child Health Insurance Research Initiative. 2003. "Who's Enrolled in the State Children's Health Insurance Program (SCHIP)? An Overview of Findings from the Child Health Insurance Research Initiative (CHIRI).” Pediatrics 112 (6, pt 2): e499. 
Call, K. T., N. Lurie, Y. Jonk, R. Feldman, and M. D. Finch. 1997. "Who Is Still Uninsured in Minnesota?" Journal of the American Medical Association 278 (14): 1191-1195.

Centers for Medicare and Medicaid Services. 2003. "State Children's Health Insurance Program-Approved Plan Files" [accessed on September 20, 2007]. Available at http://www.cms.hhs.gov/LowCostHealthInsFamChild/SCHIPASPI/

- 2007. "New York Title XXI Program Fact Sheet, November 1997 to April 2007, Inclusive" [accessed on October 15, 2007]. Available at http:// www.cms.hhs.gov/LowCostHealthInsFamChild/downloads/NYCurrentFactsheet. pdf

Child and Adolescent Health Measurement Initiative (CAHMI). 2003. "Children with Special Health Care Needs: The CSHCN Screener" [accessed on November 13, 2007]. FAACT Legacy Documents, FAACT-The Foundation for Accountability, Portland, OR. Available at http://www.markle.org/resources/faact/ doclibFiles/documentFile_466.pdf

Congressional Budget Office. 2007. "Resuming the Path to Health Coverage for Children and Parents." State Children's Health Insurance Program. Publication no. 2970; May; Kaiser Commission on Medicaid and the Uninsured. Available at http://www.kff.org/medicaid/upload/7608.pdf

Davidson, G., L. A. Blewett, and K. T. Call. 2004. "Research Synthesis Report No. 5. Public Program Crowd-Out of Private Coverage: What Are the Issues?" [accessed August 2004]. Available at http://www.rwjf.org/publications/ synthesis/reports_and_briefs/issue $5 . h t m l$

Dick, A. W., R. A. Allison, S. G. Haber, C. Brach, and E. Shenkman. 2002. "Consequences of States' Policies for SCHIP Disenrollment." Health Care Financing Review 23 (3): 65-88.

Dubay, L. 1999. Expansions in Public Health Insurance and Crowd Out: What the Evidence Says. The Kaiser Project on Incremental Health Reform. Washington, DC: The Urban Institute.

Feinberg, E., K. Swartz, A. Zaslavsky, J. Gardner, and D. Klein Walker. 2001. "Family Income and Crowd Out among Children Enrolled in Massachusetts Children's Medical Security Plan." Health Services Research 36 (6, part II): 45-63.

Glied, S. 2002. "CCrowd-Out and Public-Private Substitution,' A Review of the Literature on Crowd-Out" [accessed July 2003]. Available at http://www.ins. state.il.us/spg/Qualitative_Research_Activities.htm

Hughes, D., J. Angeles, and E. Stilling. 2002. Crowd-Out in the Healthy Families Program: Does It Exist? San Francisco: University of California Institute for Health Policy Studies.

Ku, L., and D. C. Ross. 2002. Staying Covered: The Importance of Retaining Health Insurance for Low-Income Families. New York: The Commonwealth Fund.

Landgraf, J. M., L. Abaetz, and J. E. Ware. 1996. The CHQ User's Manual. First Edition. Boston: The Health Institute, New England Medical Center.

National Conference of State Legislatures. 2003. "Crowd-Out Provisions in NonMedicaid SCHIP Plans" [updated September 30, 2003; accessed on July 10, 2005]. Available at http://www.ncsl.org/programs/health/schiptable09.htm 
National Heart, Lung, Blood Institute. 1997. "National Asthma Education and Prevention Program Expert Panel Report \#2: Guidelines for the Diagnosis and Management of Asthma." NIH Pub. 97-4051.

Nogle, J., and E. Shenkman. 2004. "Florida KidCare Evaluation Report, 2003" [accessed on July 25, 2007]. Available at http://www.ichp.ufl.edu/documents/ KidCareReportYear5Final.pdf

Olson, L. M., S. S. Tang, and P. W. Newacheck. 2005. "Children in the United States with Discontinuous Insurance Coverage." New England Journal of Medicine 353: 382-391.

Rosenbach, M., M. Ellwood, C. Irvin, C. Young, W. Conroy, B. Quinn, and M. Kell. 2003. Implementation of the State Children's Health Insurance Program: Synthesis of State Evaluations. Background for the Report to Congress. MPR Reference No.: 8644-100 Mathematica Policy Research, Cambridge, MA.

Satchell, M., and S. Pati. 2005. "Insurance Gaps among Vulnerable Children in the United States, 1991-2001.” Pediatrics 116 (5): 1155-1161.

Shenkman, E., R. Bucciarelli, D. H. Wegener, R. Naff, and S. Freedman. 1999. "Crowd Out: Evidence from the Florida Healthy Kids Program.” Pediatrics 104 3: 507513.

Shone, L. P., and P. G. Szilagyi. 2005. "The State Children's Health Insurance Program (Review)." Current Opinion in Pediatrics Vol. 17: 764-772.

Silberman, P., J. Walsh, R. Slifkin, and S. Poley. 2003. The North Carolina Health Choice Enrollment Freeze of 2001: Health Risks and Financial Hardships for Working Families. Chapel Hill, NC: Cecil G. Sheps Center for Health Services Research, University of North Carolina at Chapel Hill.

Sommers, A., S. Zuckerman, L. Dubay, and G. Kenney. 2006. "Substitution of SCHIP for Private Coverage: Results from a 2002 Evaluation in Ten States." Health Affairs 26 (2): 529-537.

StataCorp. 2007. Stata Statistical Software: Release 10. College Station, TX: StataCorp.

Strom, S. 2003. "For Middle Class, Health Insurance Becomes a Luxury" [accessed on November 16, 2003]. The New York Times, 11/16/2003. Available at http:// www.nytimes.com 